\title{
A PRÁTICA DOCENTE EPISTEMOLÓGICA DA METODOLOGIA DO ENSINO SUPERIOR
}

\section{ARTIGO ORIGINAL}

DIAS, Vagner Neves ${ }^{1}$

DIAS, Vagner Neves. A prática docente epistemológica da metodologia do ensino superior. Revista Científica Multidisciplinar Núcleo do Conhecimento. Ano 04, Ed. 03, Vol. 06, pp. 92-97. Março de 2019. ISSN: 2448-0959.

\section{RESUMO}

Este estudo de caráter exploratório e bibliográfico objetivo investigar acerca da prática docente epistemológica da metodologia do ensino superior e a formação do professor neste contexto. Os dados levantados a partir da análise das informações coletadas evidenciaram que o aumento na frequência no ensino superior, ainda que represente conquista social, fez com que a educação universitária entrasse em uma crise que excede os limites da institucionalidade, decorrente da mercadorização do Ensino Superior, a qual fez surgir a improvisação docente. Diante desta realidade, torna-se indiscutível a preocupação no que diz respeito à formação pedagógica e com o desenvolvimento de uma consciência epistemológica fundamentada na concepção de que o homem é um ser ativo e de relações sociais.

Palavras-chave: Epistemologia, Metodologia do ensino superior, Prática docente.

\section{INTRODUÇÃO}

A partir do fenômeno da globalização, "o mundo vem se tornando pequeno, homogêneo e plural" (MORAES, 1997, p. 125). Isto tem feito com que o processo educacional sofra alterações. Assim, comentam Strassburger e Velasquez (2012) que

\footnotetext{
${ }^{1}$ Mestre em Ciências da Educação, Professor, Aluno da Universidade Interamericana de Assunção - Paraguai.
} 
a constante busca por inovados ambientes de aprendizagem, tem feito com que diversas investigações sejam feitas com enfoque na Epistemologia da Metodologia da Educação Superior voltada à multidimensionalidade do processo educacional e seu novo referencial.

Nesse contexto de mudanças, o papel desempenhado pelo professor tem recebido novos contornos, e o docente passa a assumir uma função mais proativa, dinâmica e construtiva. Segundo Pinto; Araújo e Fonseca (2005, p. 1), os alicerces epistemológicos da metodologia do ensino superior colaboram essencialmente para a racionalização do processo de ensino aprendizagem. Isto porque a metodologia do ensino superior necessita ser entendida na universidade enquanto "prática que constitui um conjunto específico de conhecimentos científicos, com características específicas sobre o ensino e a pesquisa, com mecanismos e métodos próprios de exercício intelectual".

Sobre o processo de ensino aprendizagem, Coll (1994, p. 113) cita que este ocorre por meio do domínio da interação interpessoal, através da maneira como o docente proporciona aos alunos meios para que eles interajam com o objeto do conhecimento. Neste contexto, é muito importante que o professor compreenda sua função de intermediação, pois, será tal conduta que viabilizará "uma maior ou menor margem para a atividade auto-estruturante do aluno". Contudo, mencionam Pinto; Araújo e Fonseca $(2005$, p. 4 ), que o educador "em sua prática docente, se depara com problemas e dificuldades de ordem formativa, epistemológica e pedagógica". Tais "dificuldades e impasses têm reflexos diretos e imediatos na formação acadêmica e intelectual do aluno".

Dito isto, este estudo teve por objetivo investigar acerca da prática docente epistemológica da metodologia do ensino superior e a formação do professor neste contexto. 


\section{FUNDAMENTAÇÃO TEÓRICA}

Menciona Silva (2018) que diversos levantamentos científicos evidenciam deficiências na formação do docente universitário. Informa Guimarães (1997, p. 58) que em decorrência da sociedade líquida em que se vive atualmente, em que as necessidades mudam a todo o momento, as instituições de ensino superior acabam desprezando "o registro de projetos e ações extensionistas", perdendo-se com isto a possibilidade de criar história. Ocorre que segundo Ribas (2000, p. 62), "a prática pedagógica só se aperfeiçoa, por quem a realiza, a partir de sua história de vida e saberes de referência, das experiências e aspirações", pois, "é na prática e na reflexão sobre ela que o professor consolida ou revê ações, encontra novas bases e descobre novos conhecimentos".

Na práxis do ensino superior, a ação dialética se fundamenta por meio das tensões vivenciadas no dia a dia universitário. Assim, segundo Rays (2003, p. 3), estender o conhecimento por meio da extensão universitária, operacionaliza-se através "de uma práxis dialética (mediadora entre universidade-sociedade-universidade) de produção / reprodução crítica do conhecimento".

Mas, conforme defendido por Pazinat (2014, p. 348), a expansão da Educação Superior após aumento desenfreado do volume de matrículas, "proliferação de instituições e cursos repercutiu na desestabilização da formação docente, desencadeando o fenômeno denominado improvisação docente".

Santos (2004) evidencia que a educação universitária passa por sérias crises, as quais ultrapassam os limites de ser apenas institucional, atingindo também os âmbitos da hegemonia e da legitimidade. Desse modo, para Pazinat (2014, p. 349) a universidade transformou-se em verdadeiras fábricas de dinheiro (capitalismo educacional), perdeu o seu cunho educacional e virou empresa. "Nesta perspectiva, percebe-se o quanto é considerado importante o professor altamente capacitado em sua área específica, técnica e fechada" (PAZINAT, 2014, p. 352), uma vez que no processo educacional a ênfase deve ser dada à aprendizagem e não ao ensino, no qual o docente se via como "dono" da situação e do saber. 
Assim, diversas instituições vêm se dedicando ao processo de formação continuada para os professores de nível superior. No Brasil, o primeiro órgão a prestar assessoria pedagógica ao professor de nível superior foi o Laboratório de Ensino Superior da Faculdade de Educação no estado do Rio Grande do Sul (BERBEL, 1994). Segundo Pazinat (2014, p. 355), ser professor é uma missão complexa e trabalhosa, a qual solicita responsabilidade e comprometimento, por isso "requer formação pedagógica, conhecimento, criatividade, criticidade, sabedoria, competência, disponibilidade e disposição".

Assim, se em meio à teoria e a prática existe a didática organizando o processo de ensino, há também, "complementando a didática, a metodologia de ensino, que se refere aos meios utilizados pelo docente para apresentar o conteúdo, discutir e avaliar os alunos" (TEIXEIRA, 2018, p.35).

É importante que se compreenda que ensinar exige a aplicação de métodos, pois o verdadeiro ensinar ocorre quando no âmbito educacional se partilha com o outro, ou com um grupo, experiências e saberes acumulados. E, para que isto aconteça, é necessária a observação de técnicas.

Levando-se em consideração o fato de que é no processo de aprendizagem que se trabalha com diversificados objetivos, Masetto (2012) menciona a necessidade da aplicação de várias técnicas, sendo imprescindível que o docente tenha conhecimento técnico sobre estas para conduzir com maior eficácia suas aulas. Nesse sentido, para o referido autor é preciso que o docente:

- tenha conhecimento de várias técnicas ou estratégias, bem como o domínio do uso destas para poder utilizá-las em aula;

- desenvolva capacidade de adaptação das diversas técnicas, modificando-as naquilo que for necessário para que possam ser usadas com aproveitamento pelos alunos individualmente ou em grupos (MASETTO, 2012, p. 103). 
Além de "que, pelo conhecimento e domínio prático de muitas técnicas e por sua capacidade de adaptação das técnicas existentes, se torne capaz de criar novas técnicas" capazes de melhorar e dar respostas satisfatórias "às necessidades de seus alunos. Afinal, técnicas são instrumentos e como tais podem ser criadas por aqueles que vão usá-las" (MASETTO, 2012, p. 103).

As bases epistemológicas da metodologia do ensino superior apontam que não há técnica cristalizada, ou mesmo universal passível de ser aplicada de maneira mecânica. O que existem na verdade são sugestões, as quais poderão ser readaptadas, reorganizadas, reinventadas pelo docente em seu cotidiano prático, de acordo com as situações apresentadas e os objetivos propostos.

Assim, compreende-se que epistemologicamente compete ao professor compreender o papel relevante de mediador que desenvolve no âmbito de sua práxis docente, preparando, organizando, controlando e dirigindo as atividades; e manipulando adequadamente as estratégias mais eficazes ao alcance dos objetivos e ao aprendizado dos alunos. Para tanto, é necessário que este profissional conheça a realidade de seus alunos e do problema que enfrenta, tomando consciência de sua concepção epistemológica.

O ponto fundamental da Epistemologia da Metodologia do Ensino Superior defende a premissa de que o homem é um ser ativo e de relações sociais. Desse modo, "o conhecimento não pode ser transferido, mas construído nas suas ligações com o outro e com o mundo" (TEIXEIRA, 2018, p.37). Nessa perspectiva, cabe ao professor criar circunstâncias capazes de despertar no discente o interesse em buscar o conhecimento. E, para tanto, a utilização de mecanismos de aprendizagem mais dinâmicos faz-se imperativos, uma vez que por meio destes tornar-se-ia possível o desenvolvimento de uma ação didática reflexiva, oferecendo aos alunos mecanismos propícios para os levarem a um estado de mudança. 


\section{CONSIDERAÇÕES FINAIS}

Diante dos dados coletados mediante o levantamento bibliográfico realizado, chegase a compreensão de que o aumento na frequência no ensino superior, ainda que seja uma conquista social, fez com que a educação universitária entrasse em uma crise que excede os limites da institucionalidade, decorrente da mercadorização do Ensino Superior, surgindo a improvisação docente, ou seja, profissionais sendo contratados como professores, ainda que não possuam uma formação pedagógica, a qual é essencial para que estes atuem satisfatoriamente e desenvolvam o papel para o qual foram contratados com maestria.

Diante desta realidade, torna-se indiscutível a preocupação no que diz respeito à formação pedagógica e com o desenvolvimento de uma consciência epistemológica fundamentada na concepção de que o homem é um ser ativo e de relações sociais. Assim, não existe uma fórmula pronta ou um método de ensino universal; as estratégias, as técnicas devem ser aplicadas e criadas conforme a necessidade e realidade do aluno, e estas, por sua vez, devem ser criativas e interativas de modo a conduzir o aluno a um estado de mudança, tornando-o um ser crítico e capaz de atuar em um mercado que se mostra cada vez mais dinâmico e proativo.

\section{REFERÊNCIAS}

BERBEL, Neusi Aparecida Navas. Metodologia do ensino superior: realidade e significado. Coleção magistério formação e trabalho pedagógico. Campinas: Papirus, 1994.

COLL, César. Aprendizagem escolar e construção do conhecimento. Porto Alegre: Artes Médicas, 1994.

GUIMARÃES, A. M. M. Extensão universitária como reconfiguração de Saberes. In: E: LEITE, D. MOROSINI, M. (ORG) Universidade Futurante: produção do ensino e inovação. Campinas: Papirus, 1997. 
MASETTO, Marcos Tarcísio. Competência pedagógica do professor universitário. 2. ed. São Paulo: Summus, 2012.

MORAES, Maria Cândida. O paradigma educacional emergente. Campinas, SP: Papirus, 1997.

PAZINAT, Aldiciane, Universidade e formação docente. Anais. Colóquio Internacional de Educação. Eixo Temático 2: Organização e Gestão da Educação Básica e Superior. Santa Catarina, 2014.

PINTO, Celeida Garcia Cintra.; ARAÚJO, Clara Lila Gonzalez de.; FONSECA, Dirce Mendes da. A prática docente das bases epistemológicas da metodologia científica no ensino superior.Brasília: Centro Universitário de Brasília, 2005.

RAYS, Oswaldo Alonso. Ensino-pesquisa-extensão: notas para pensar a indissociabilidade. Palestra proferida. Santa Maria, 2003.

RIBAS, Mariná Holzmann. Construindo a competência: processo de formação de professores. São Paulo: Olho d'Água, 2000.

SANTOS, Boaventura de Sousa. A Universidade no Século XXI: para uma Reforma Democrática e Emancipatória da Universidade. São Paulo: Cortez, 2004.

SILVA, Regina Nogueira da. A Importância da Didática no Ensino Superior. Disponível em:

<http://www.ice.edu.br/TNX/storage/webdisco/2011/11/10/outros/75a110bfebd8a889 54e5f511ca9bdf8c.pdf>. Acesso em: jan. de 2018

STRASSBURGER, Nândri Cândida.; VELASQUEZ, Guilherme Garcia. O Ensino Superior: a epistemologia da prática profissional. Anais. VII Seminário de pesquisa em Turismo do Mercosul. Novembro de 2012. Disponível em: $<$ https://www.ucs.br/ucs/eventos/seminarios_semintur/semin_tur_7/arquivos/01/03_S trassburger_Velazquez.pdf>. 
TEIXEIRA, Maria Cláudia. Metodologia do ensino superior. Paraná: UNICENTRO.

Disponível em:

$<$ http://repositorio.unicentro.br:8080/jspui/bitstream/123456789/984/5/Metodologia\%2 0do\%20ensino\%20superior.pdf>. Acesso em: dez. de 2018.

Enviado: Fevereiro, 2019.

Aprovado: Março, 2019. 